NASA/TM-2000-210516

$\mathrm{N}=3 \mathrm{~A}$

Local Mesh Refinement in the Space-Time CE/SE Method

Sin-Chung Chang

Glenn Research Center, Cleveland, Ohio

Yuhui Wu

Pennsylvania State University, University Park, Pennsylvania

Xiao-Yen Wang

Taitech Inc., Cleveland, Ohio

Vigor Yang

Pennsylvania State University, University Park, Pennsylvania 
Since its founding, NASA has been dedicated to the advancement of aeronautics and space science. The NASA Scientific and Technical Information (STI) Program Office plays a key part in helping NASA maintain this important role.

The NASA STI Program Office is operated by Langley Research Center, the Lead Center for NASA's scientific and technical information. The NASA STI Program Office provides access to the NASA STI Database, the largest collection of aeronautical and space science STI in the world. The Program Office is also NASA's institutional mechanism for disseminating the results of its research and development activities. These results are published by NASA in the NASA STI Report Series, which includes the following report types:

- TECHNICAL PUBLICATION. Reports of completed research or a major significant phase of research that present the results of NASA programs and include extensive data or theoretical analysis. Includes compilations of significant scientific and technical data and information deemed to be of continuing reference value. NASA's counterpart of peerreviewed formal professional papers but has less stringent limitations on manuscript length and extent of graphic presentations.

- TECHNICAL MEMORANDUM. Scientific and technical findings that are preliminary or of specialized interest, e.g., quick release reports, working papers, and bibliographies that contain minimal annotation. Does not contain extensive analysis.

- CONTRACTOR REPORT. Scientific and technical findings by NASA-sponsored contractors and grantees.
- CONFERENCE PUBLICATION. Collected papers from scientific and technical conferences, symposia, seminars, or other meetings sponsored or cosponsored by NASA.

- SPECIAL PUBLICATION. Scientific, technical, or historical information from NASA programs, projects, and missions, often concerned with subjects having substantial public interest.

- TECHNICAL TRANSLATION. Englishlanguage translations of foreign scientific and technical material pertinent to NASA's mission.

Specialized services that complement the STI Program Office's diverse offerings include creating custom thesauri, building customized data bases, organizing and publishing research results... even providing videos.

For more information about the NASA STI Program Office, see the following:

- Access the NASA STI Program Home Page at http://www.sti.nasa.gov

- E-mail your question via the Internet to help@sti.nasa.gov

- Fax your question to the NASA Access Help Desk at 301-621-0134

- Telephone the NASA Access Help Desk at $301-621-0390$

- Write to: NASA Access Help Desk NASA Center for AeroSpace Information 7121 Standard Drive Hanover, MD 21076 
NASA/TM-2000-210516

\section{Local Mesh Refinement in the Space-Time CE/SE Method}

Sin-Chung Chang

Glenn Research Center, Cleveland, Ohio

Yuhui Wu

Pennsylvania State University, University Park, Pennsylvania

Xiao-Yen Wang

Taitech Inc., Cleveland, Ohio

Vigor Yang

Pennsylvania State University, University Park, Pennsylvania

Prepared for the

First International Conference on Computational Fluid Dynamics sponsored by Japan Computational Fluid Dynamics Society

Kyoto, Japan, July 10-14, 2000

National Aeronautics and

Space Administration

Glenn Reseärch Center 


\section{Available from}

NASA Center for Aerospace Information 7121 Standard Drive Hanover, MD 21076

Price Code: A03
National Technical Information Service 5285 Port Royal Road Springfield, VA 22100 Price Code: A03

Available electronically at http://gltrs.grc.nasa.gov/GLTRS 


\title{
Local Mesh Refinement in the Space-Time CE/SE Method
}

\author{
Sin-Chung Chang \\ National Aeronautics and Space Administration \\ Glenn Research Center \\ Cleveland, Ohio 44135 \\ Yuhui Wu and Vigor Yang \\ Department of Mechanical Engineering \\ Pennsylvania State University \\ University Park, Pennsylvania 16802 \\ Xiao-Yen Wang \\ Taitech, Inc. \\ Cleveland, Ohio 44135
}

\begin{abstract}
A local mesh refinement procedure for the CE/SE method which does not use an iterative procedure in the treatments of grid-to-grid communications is described. It is shown that a refinement ratio in the order of 10 can be applied successfully across a single coarse grid/fine grid interface.
\end{abstract}

\section{Introduction}

To accurately resolve flow properties in high-gradient regions without applying a very fine and costly uniform grid over the entire computational domain, simulation of practical unsteady CFD problems may require implementation of local mesh refinement (LMR) in both spatial and temporal directions. In this paper, we report a new LMR procedure for the CE/SE method [1-3].

It is a must for a LMR procedure to enforce space-time flux conservation across a coarse grid/fine grid interface so that numerical solutions will not be contaminated by spurious reflections originating there [4]. Fortunately, this requirement can be met easily in the $\mathrm{CE} / \mathrm{SE}$ setting. In particular, an iterative procedure is not needed in the treatments of grid-to-grid communications. Furthermore, it will be shown that a refinement ratio in the order of 10 can be applied successfully across a single interface.

\section{Preliminaries}

To simplify the description of the LMR procedure, consider the PDE

$$
\partial u / \partial t+a \partial u / \partial x=0
$$

and its conservation form

$$
\oint_{S(V)} h \cdot d s=0
$$

where (i) $a>0$ is a constant; (ii) $S(V)$ is the boundary of any region $V$ in space-time; (iii) $h=(a u, u)$; and (iv) $d s=d \sigma n$ with $d \sigma$ and $n$, respectively, 
being the area and the outward unit normal of a surface element on $S(V)$. Note that $\boldsymbol{h} \cdot d \boldsymbol{s}$ is the flux of $\boldsymbol{h}$ leaving $V$ through the surface element $d \boldsymbol{s}$.

Let $\Omega_{1}$ denote the set of all mesh points $(j, n)$ (dots in Fig. 1) with $j+n$ being odd integers. For each $(j, n) \in \Omega_{1}$, let the solution element $\operatorname{SE}(j, n)$ be the interior of the space-time region bounded by a dashed curve depicted in Fig. 2). For any $(x, t) \in \operatorname{SE}(j, n)$, let $u(x, t)$ and $h(x, t)$, respectively, be approximated by $u^{*}(x, t ; j, n)$ and $h^{*}(x, t ; j, n)$, where [1]

$$
\begin{gathered}
u^{*}(x, t ; j, n)=u_{j}^{n}+\left(u_{x}\right)_{j}^{n}\left(x-x_{j}\right)+\left(u_{t}\right)_{j}^{n}\left(t-t^{n}\right) \\
h^{*}(x, t ; j, n)=\left(a u^{*}(x, t ; j, n), u^{*}(x, t ; j, n)\right)
\end{gathered}
$$

It is required that $u=u^{*}(x, t ; j, n)$ satisfy Eq. (1). Thus

$$
\left(u_{t}\right)_{j}^{n}=-a\left(u_{x}\right)_{j}^{n}
$$

Hereafter, $\boldsymbol{q}_{j}^{n}$ denotes the column matrix formed by $u_{j}^{n}$ and $\left(u_{x}\right)_{j}^{n}$, the independent marching variables at $(j, n) \in \Omega_{1}$.

Let space-time be divided into conservation elements (CEs). Two CEs, i.e., $\mathrm{CE}_{-}(j, n)$ and $\mathrm{CE}_{+}(j, n)$ (Figs. 3-4) are assigned to each $(j, n) \in \Omega_{1}$. Because the boundary of $\mathrm{CE}_{-}(j, n)\left(\mathrm{CE}_{+}(j, n)\right)$ lies within the union of $\mathrm{SE}(j, n)$ and $\operatorname{SE}(j-1, n-1)(\operatorname{SE}(j+1, n-1)), \boldsymbol{q}_{j}^{n}$ can be solved for in terms of $\boldsymbol{q}_{j \pm 1}^{n-1}$ by substituting $V=C E_{ \pm}(j, n)$ and $h=h^{*}$ in Eq. (2). The resulting scheme is the $a$ scheme which has the property that the flux of $h^{*}$ is conserved over the union of any combination of CEs [1].

For the $a-\epsilon$ scheme [1], which reduces to the a scheme if $\epsilon=0$, again $\boldsymbol{q}_{j}^{n}$ is a function of $\boldsymbol{q}_{j \pm 1}^{n-1}$. However, the flux of $\boldsymbol{h}^{*}$ generally is not conserved over the CEs referred to above. Rather, for each $(j, n) \in \Omega_{1}$, it is conserved over $\operatorname{CE}(j, n)$ (the union of $\mathrm{CE}_{ \pm}(j, n)$-see Fig. 5). To proceed further, in the following, the concept of modified flux will be introduced.

By definition, the modified flux at each of the line segments $\overline{A B}, \overline{B C}, \overline{C D}$ $\overline{D E}, \overline{E F}$, and $\overline{F A}$, which form the boundary of $\operatorname{CE}(j, n)$, is the corresponding flux of $h^{*}$. On the other hand, the modified flux at $\overline{A D}$, i.e., the interface that divides $\mathrm{CE}_{ \pm}(j, n)$, is defined such that the total modified flux leaving the boundary of $\mathrm{CE}_{-}(j, n)$ vanishes. Note that the modified flux at $\bar{A} \bar{D}$, except in the case of the $a$ scheme, is not equal to the corresponding flux of $h^{*}$. Because (i) the total modified flux leaving the boundary of $\mathrm{CE}(j, n)$ vanishes; and (ii) the modified flux leaving $\mathrm{CE}_{-}(j, n)$ through $\overline{A D}$ is the negative of that leaving $\mathrm{CE}_{+}(j, n)$ through $\overline{A D}$, one concludes that the total modified flux leaving the boundary of $\mathrm{CE}_{+}(j, n)$ also vanishes. In other words, the modified flux is conserved over $\mathrm{CE}_{ \pm}(j, n)$ at each $(j, n) \in \Omega_{1}$.

The $a-\epsilon$ scheme obviously can also be defined over $\Omega_{2}$, the set of $(j, n)$ (not marked in Fig. 1) with $j+n$ being even integers. Moreover, two schemes defined over $\Omega_{1}$ and $\Omega_{2}$ can be fused into a "dual" scheme which is defined over $\Omega \stackrel{\text { def }}{=}$ $\Omega_{1} \cup \Omega_{2}$. Note that, in practical applications, a solution of a dual scheme may not be decoupled into two independent solutions. 
Let $(j, n) \in \Omega_{1}$, then $(j+1, n) \in \Omega_{2}$. By definition, $\mathrm{CE}_{+}(j, n)$ coincides with $\mathrm{CE}_{-}(j+1, n)$. However, two different flux conservation conditions are defined over their co-boundary. In fact, two different modified fluxes tied to, respectively, these two coincident CEs, are defined at any boundary line segment. Obviously, the same complication arises for any CE. As a result, in case that the solution of a dual scheme becomes coupled, the concept of global flux conservation is not well defined in terms of these individual modified fluxes. However, if the generalized fux at any line segment that forms the boundary of a $C E$ is defined as the average of the two local modified fluxes, then the generalized flux is conserved over the union of any combination of CEs. The proof follows from (i) the generalized flux is conserved over each $\mathrm{CE}$ - a fact that can be established by summing over the two local modified flux conservation conditions tied to this $\mathrm{CE}$; and (ii) the generalized flux leaving one $\mathrm{CE}$ through an interface is the negative of that leaving the neighboring $\mathrm{CE}$ through the same interface.

\section{Time Marching}

As an example, a step-by-step description of the marching from the 0th to 1st time level (Fig. 6) will be described. Note that (i) the simple grid structure used here does not limit the generality of the following discussions; and (ii) two $q s$ and thus two symbols (e.g., $A_{3}^{\mathrm{l}}$ and $B_{1}^{\mathrm{l}}$ ) are assigned to any common mesh point of a coarse grid and a fine grid.

I. Because $a>0, q\left(A_{1}^{1}\right)$ is specified as a part of the left boundary condition while $\boldsymbol{q}\left(C_{3}^{1}\right)$ is extrapolated from $\boldsymbol{q}\left(C_{2}^{0}\right)$, i.e., $\boldsymbol{q}\left(C_{3}^{1}\right)=\boldsymbol{q}\left(C_{2}^{0}\right)$.

II. $\boldsymbol{q}\left(A_{2}^{1}\right)$ is determined in terms of $\boldsymbol{q}\left(A_{1}^{0}\right)$ and $\boldsymbol{q}\left(A_{3}^{0}\right)$ using the dual $a-\epsilon$ scheme with $\epsilon=0.5$ [1]. Similarly, $q\left(B_{2}^{1 / 2}\right)\left(q\left(C_{2}^{1}\right)\right)$ is determined in terms of $q\left(B_{1}^{0}\right)$ and $\boldsymbol{q}\left(B_{3}^{0}\right)\left(\boldsymbol{q}\left(C_{1}^{0}\right)\right.$ and $\left.\boldsymbol{q}\left(C_{3}^{0}\right)\right)$.

III. $\boldsymbol{q}\left(B_{1}^{1 / 2}\right)$ is determined in terms of $\boldsymbol{q}\left(A_{2}^{0}\right), \boldsymbol{q}\left(A_{3}^{0}\right)$ and $\boldsymbol{q}\left(B_{2}^{0}\right)$ assuming

$$
\begin{gathered}
u_{x}\left(B_{1}^{1 / 2}\right)=\left[u\left(B_{1}^{1 / 2}\right)-\left(u\left(A_{2}^{0}\right)+(\Delta t / 2) u_{t}\left(A_{2}^{0}\right)\right)\right] / \Delta x \\
F\left(\overrightarrow{A_{3}^{0} B_{1}^{1 / 2}}\right)+F\left(\overrightarrow{B_{1}^{1 / 2} B_{2}^{1 / 2}}\right)+F\left(\overrightarrow{B_{2}^{0} B_{2}^{1 / 2}}\right)+F\left(\overrightarrow{B_{2}^{0} B_{1}^{0}}\right)=0
\end{gathered}
$$

Here (i) $u_{t}\left(A_{2}^{0}\right)=-a u_{x}\left(A_{2}^{0}\right)$ (see Eq. (5)); and (ii) $F\left(\overrightarrow{A_{3}^{0} B_{1}^{1 / 2}}\right.$ ), as an example, denotes the flux of $h^{*}$ leaving the rectangle $A_{3}^{0} B_{1}^{1 / 2} B_{2}^{1 / 2} B_{2}^{0}$ through $\overline{A_{3}^{0} B_{1}^{1 / 2}}$ as evaluated using $\boldsymbol{q}\left(A_{3}^{0}\right)$. Similarly, $\boldsymbol{q}\left(B_{3}^{1 / 2}\right)$ is determined in terms of $\boldsymbol{q}\left(B_{2}^{0}\right), \boldsymbol{q}\left(C_{1}^{0}\right)$ and $\boldsymbol{q}\left(C_{2}^{0}\right) . \boldsymbol{q}\left(B_{2}^{1}\right)$ is then determined in terms of $\boldsymbol{q}\left(B_{1}^{1 / 2}\right)$ and $\boldsymbol{q}\left(B_{3}^{1 / 2}\right)$ using the special dual $a-\epsilon$ scheme referred to above.

IV. $\boldsymbol{q}\left(B_{1}^{1}\right)$ is determined in terms of $\boldsymbol{q}\left(B_{2}^{1 / 2}\right), \boldsymbol{q}\left(A_{3}^{0}\right)$ and $\boldsymbol{q}\left(A_{2}^{0}\right)$ assuming

$$
\begin{gathered}
u_{x}\left(B_{1}^{1}\right)=\left[u\left(B_{1}^{1}\right)-\left(u\left(A_{2}^{0}\right)+\Delta t u_{t}\left(A_{2}^{0}\right)\right)\right] / \Delta x \\
F\left(A_{3}^{0}, \overline{B_{1}^{1 / 2} B_{1}^{1}}\right)+F\left(\overrightarrow{B_{1}^{1} B_{2}^{1}}\right)+F\left(\overrightarrow{B_{2}^{1 / 2} B_{2}^{1}}\right)+F\left(\overrightarrow{B_{2}^{1 / 2} B_{1}^{1 / 2}}\right)=0
\end{gathered}
$$


Here $F\left(A_{3}^{0}, \overline{B_{1}^{1 / 2} B_{1}^{1}}\right)$ denotes the flux of $h^{*}$ at $\overline{B_{1}^{1 / 2} B_{1}^{1}}$ evaluated using $q\left(A_{3}^{0}\right)$. Similarly, $\boldsymbol{q}\left(B_{3}^{1}\right)$ is determined in terms of $q\left(B_{2}^{1 / 2}\right), q\left(C_{1}^{0}\right)$ and $q\left(C_{2}^{0}\right)$.

V. $\boldsymbol{q}\left(A_{3}^{1}\right)$ is determined in terms of $\boldsymbol{q}\left(B_{1}^{0}\right), \boldsymbol{q}\left(B_{1}^{1 / 2}\right), \boldsymbol{q}\left(B_{2}^{1 / 2}\right)$ and $\boldsymbol{q}\left(A_{2}^{0}\right)$ assuming

$$
\begin{gathered}
u_{x}\left(A_{3}^{1}\right)=\left[\left(u\left(B_{2}^{1 / 2}\right)+(\Delta t / 2) u_{t}\left(B_{2}^{1 / 2}\right)\right)-u\left(A_{3}^{1}\right)\right] /(\Delta x / 2) \\
F\left(\overrightarrow{B_{1}^{0} B_{1}^{1 / 2}}\right)+F\left(\overrightarrow{B_{1}^{1 / 2} B_{1}^{1}}\right)+F\left(\overrightarrow{A_{3}^{1} A_{2}^{1}}\right)+F\left(\overrightarrow{A_{2}^{0} A_{2}^{1}}\right)+F\left(\overrightarrow{A_{2}^{0} A_{3}^{0}}\right)=0
\end{gathered}
$$

Similarly, $\boldsymbol{q}\left(C_{1}^{1}\right)$ is determined in terms of $\boldsymbol{q}\left(B_{3}^{0}\right), \boldsymbol{q}\left(B_{3}^{1 / 2}\right), \boldsymbol{q}\left(B_{2}^{1 / 2}\right)$ and $\boldsymbol{q}\left(C_{2}^{0}\right)$.

Note that, at each line segment on a coarse grid/fine grid interface, two fluxes of $h^{*}$ are evaluated using a coarse-grid $\boldsymbol{q}$ and a fine-grid $\boldsymbol{q}$, respectively. Moreover, each of these fluxes is involved in a coarse-grid conservation condition and a fine-grid conservation condition. As a result, for the current marching procedure, it can be shown that the generalized fux is conserved over the union of any combination of interior CEs.

\section{Mesh Reconstruction}

For time-dependent problems, spatial mesh reconstruction may be implemented at any designated time level such that high-gradient regions are always covered by fine grids. In the following, a step-by-step description of a reconstruction procedure that preserves generalized-flux conservation will be explained using Fig. 7 (Note: $C_{3 / 2}$ is the midpoint of $\overline{C_{1} C_{2}}$ ).

I. No reconstruction is required for the mesh points to the left of $A_{2}$ or to the right of $C_{2}$. Thus $\boldsymbol{q}\left(A_{1}^{\prime}\right)=\boldsymbol{q}\left(A_{1}\right)$ and $\boldsymbol{q}\left(C_{2}^{\prime}\right)=\boldsymbol{q}\left(C_{3}\right)$.

II. $\boldsymbol{q}\left(A_{2}^{\prime}\right)$ is determined in term of $\boldsymbol{q}\left(A_{2}\right), \boldsymbol{q}\left(B_{1}\right)$ and $\boldsymbol{q}\left(B_{2}\right)$ assuming

$$
F\left(\overrightarrow{A_{2}^{\prime} A_{1}}\right)=F\left(\overrightarrow{A_{2} A_{1}}\right), \quad F\left(\overrightarrow{A_{2}^{\prime} A_{3}^{\prime}}\right)=F\left(\overrightarrow{B_{1} B_{2}}\right)+F\left(\overrightarrow{B_{2} B_{3}}\right)
$$

III. $\boldsymbol{q}\left(B_{2}^{\prime}\right)$ is determined in terms of $\boldsymbol{q}\left(C_{1}\right)$ and $\boldsymbol{q}\left(C_{2}\right)$ assuming

$$
F\left(\overrightarrow{B_{2}^{\prime} B_{1}}\right)=F\left(C_{2}, \overline{C_{3 / 2} C_{1}}\right), \quad F\left(\overrightarrow{B_{2}^{\prime} B_{3}^{\prime}}\right)=F\left(C_{1}, \overline{C_{3 / 2} C_{2}}\right)
$$

IV. $q\left(A_{3}^{\prime}\right)$ is determined in terms of $q\left(B_{2}\right), q\left(B_{3}\right)$ and $q\left(B_{2}^{\prime}\right)$ assuming

$u_{x}\left(A_{3}^{\prime}\right)=\left(u\left(B_{2}^{\prime}\right)-u\left(A_{3}^{\prime}\right)\right) /(\Delta x / 2), \quad F\left(\overrightarrow{A_{3}^{\prime} A_{2}^{\prime}}\right)=F\left(\overrightarrow{B_{3} B_{2}}\right)+F\left(\overrightarrow{B_{2} \overrightarrow{B_{1}}}\right)$

V. $\boldsymbol{q}\left(B_{1}^{\prime}\right)$ is determined in terms of $\boldsymbol{q}\left(C_{1}\right)$ and $\boldsymbol{q}\left(A_{2}^{\prime}\right)$ assuming

$$
u_{x}\left(B_{1}^{\prime}\right)=\left(u\left(B_{1}^{\prime}\right)-u\left(A_{2}^{\prime}\right)\right) / \Delta x, \quad F\left(\overrightarrow{B_{1}^{\prime} B_{2}^{\prime}}\right)=F\left(\overrightarrow{C_{1} C_{3 / 2}}\right)
$$

VI. $\boldsymbol{q}\left(B_{3}^{\prime}\right)$ is determined in terms of $\boldsymbol{q}\left(C_{2}\right)$ and $\boldsymbol{q}\left(C_{2}^{\prime}\right)$ assuming

$$
u_{x}\left(B_{3}^{\prime}\right)=\left(u\left(C_{2}^{\prime}\right)-u\left(B_{3}^{\prime}\right)\right) / \Delta x, \quad F\left(\overrightarrow{B_{3}^{\prime} B_{2}^{\prime}}\right)=F\left(\overrightarrow{C_{2} C_{3 / 2}}\right)
$$

VII. $\boldsymbol{q}\left(C_{1}^{\prime}\right)$ is determined in terms of $\boldsymbol{q}\left(C_{2}\right)$ and $\boldsymbol{q}\left(B_{2}^{\prime}\right)$ assuming

$$
u_{x}\left(C_{1}^{\prime}\right)=\left(u\left(C_{1}^{\prime}\right)-u\left(B_{2}^{\prime}\right)\right) /(\Delta x / 2), \quad F\left(\overrightarrow{C_{1}^{\prime} C_{2}^{\prime}}\right)=F\left(\overrightarrow{C_{2} C_{3}}\right)
$$




\section{Numerical Results}

Assuming $a=1, \Delta x=0.01$ and $\Delta t=0.009$, an exact solution to Eq. (1), i.e.,

$$
u=(10 / \sqrt{\pi}) \exp \left[-100(x-t-0.3)^{2}\right]
$$

is solved numerically using the current LMR procedure with a grid refinement ratio $R=10$ in both space and time. The initial condition ( $t=0)$ and mesh distribution are shown in Fig. 8 while the exact solution (a solid line) and numerical solution (dots) along with the mesh distribution at $t=0.9$ are depicted in Fig. 9 (Note: due to a consideration related to generalized flux, here each dot represents a midpoint solution, i.e., the average mesh value of two neighboring mesh points). It is seen that the numerical solution match very smoothly across the two coarse grid/fine grid interfaces.

Assuming $\Delta x=4 \times 10^{-3}, \Delta t=1.5 \times 10^{-3}$ and $R=4$, the Sod's shock tube problem $[1]$ is also solved using a similar Euler LMR procedure. The results at $t=0.195$ are shown in Fig. 10(a) while a close-up view covering only the neighborhoods of grid interfaces is depicted in Fig. 10(b). Note that a simulation using $R=64$ also has been carried out successfully.

\section{Conclusions}

A simple CE/SE LMR procedure has been described. Its robustness is demonstrated by numerical examples with grid refinement in the order of 10 .

\section{References}

[1] S.C. Chang: The method of space-time conservation element and solution element - A new approach for solving the Navier-Stokes and Euler equations. J. Computational Physics, 119, 1995, pp. 295-324.

[2] S.C. Chang, X.Y. Wang, and C.Y. Chow: The space-time conservation element and solution element method - A new high-resolution and genuinely multidimensional paradigm for solving conservation laws. J. Computational Plysics, 156, 1999, pp. 89-136.

[3] Other CE/SE references: www.grc.nasa.gov/www/microbus.

[4] M.J. Berger: On conservation at grid interfaces. SIAM J. Numer. Anal., 24(5), 1986, pp. 967-984. 

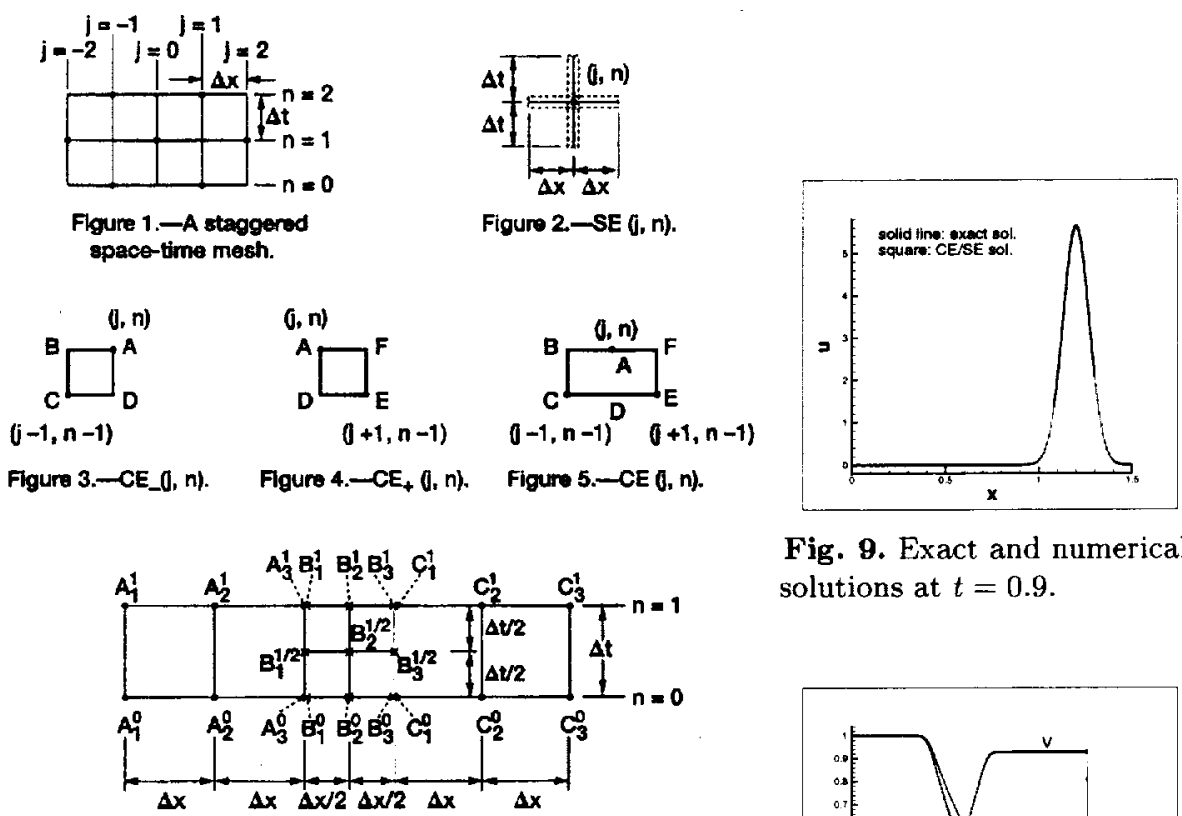

Flgure 6. A coarse-grid/fine-grid space-time mesh.

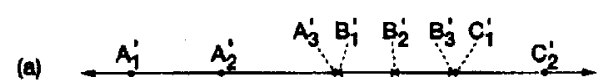

Fig. 9. Exact and numerical solutions at $t=0.9$.

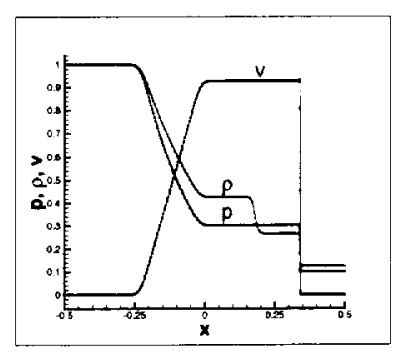

(b)

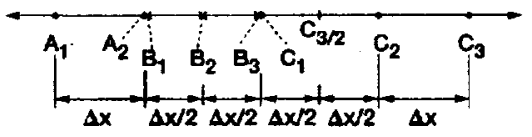

Figure 7. Mesh reconstruction. (a) Reconstructed meeh. (b) Original mesh.
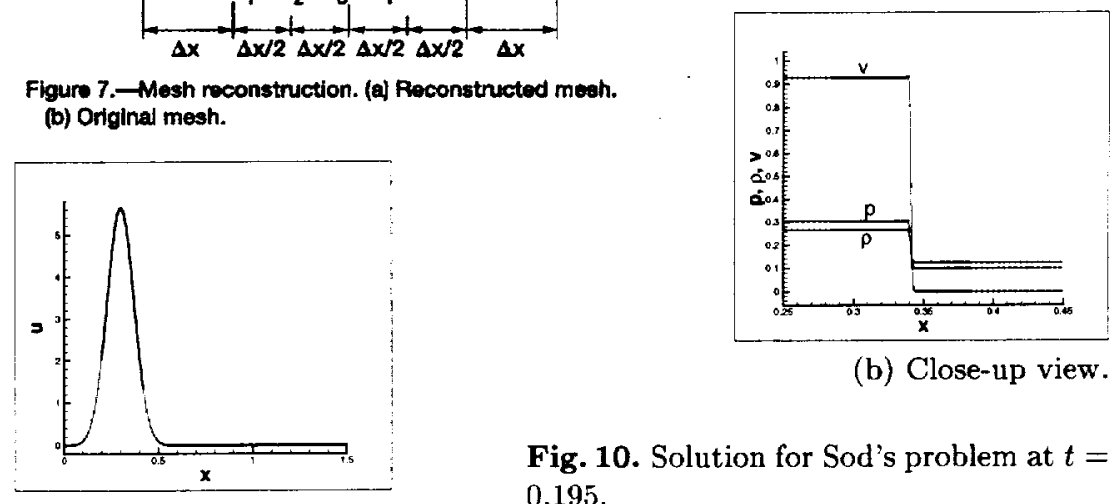

(b) Close-up view.

Fig. 10. Solution for Sod's problem at $t=$ 0.195 .

Fig. 8. Initial condition (Eq. (18)). 
Public reporting burden for this collection of information is estimated to average 1 hour per response, including the time for reviewing instructions, searching existing data sources, gathering and maintaining the data needed, and completing and reviewing the collection of intormation. Send comments regarding this burden estimate or any other aspect of this

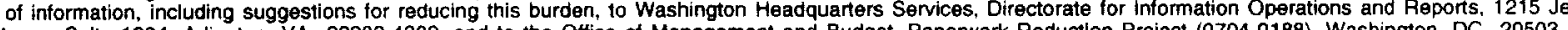

Davis Highway, Sulte 1204, Artington, VA 22202-4302, and to the Office of Management and Budget, Papenwork Peductlon Project (0704-0188), Washington, DC 20503.

\begin{tabular}{|l|l|l|}
\hline 1. AGENCY USE ONLY (Leave blank) & 2. REPORT DATE & 3. REPORT TYPE AND DATES COVERED
\end{tabular}

\begin{tabular}{l|l|l} 
October 2000 \\
\hline
\end{tabular}

4. TITLE AND SUBTITLE

Technical Memorandum

Local Mesh Refinement in the Space-Time CE/SE Method

6. AUTHOR(S)

Sin-Chung Chang, Yuhui Wu, Vigor Yang, and Xiao-Yen Wang

7. PERFORMING ORGANIZATION NAME(S) AND ADDRESS(ES)

8. PERFORMING ORGANIZATION

REPORT NUMBER

National Aeronautics and Space Administration

John H. Glenn Research Center at Lewis Field

Cleveland, Ohio 44135-3191

E-12484

9. SPONSORINGMONITORING AGENCY NAME(S) AND ADDRESS(ES)

10. SPONSORINGMONITORING AGENCY REPORT NUMBER

National Aeronautics and Space Administration

Washington, DC 20546-0001

NASA TM-2000-210516

11. SUPPLEMENTARY NOTES

Prepared for the First International Conference on Computational Fluid Dynamics sponsored by Japan Computational Fluid Dynamics Society, Kyoto, Japan, July 10-14, 2000. Sin-Chung Chang, NASA Glenn Research Center; Yuhui Wu and Vigor Yang, Pennsylvania State University, Department of Mechanical Engineering, University Park, Pennsylvania 16802; Xiao-Yen Wang, Taitech Inc., 21000 Brookpark Rd., Cleveland, Ohio 44135. Responsible person, Sin-Chung Chang, organization code 5880, 216-433-5874.

\begin{tabular}{l|l|l} 
128. DISTRIBUTION/AVAILABILITY STATEMENT & 12b. DISTRIBUTION CODE
\end{tabular}

Unclassified - Unlimited

Subject Categories: 34 and 64

Distribution: Nonstandard

Available electronically at http://gltrs. grc,nasa.gov/GLTRS

This publication is available from the NASA Center for AeroSpace Information. 301-621-0390.

13. ABSTRACT (Maximum 200 words)

A local mesh refinement procedure for the CE/SE method which does not use an iterative procedure in the treatments of grid-to-grid communications is described. It is shown that a refinement ratio higher than 10 can be applied successfully across a single coarse grid/fine grid interface.

\begin{tabular}{|c|c|c|c|}
\hline \multicolumn{3}{|c|}{$\begin{array}{l}\text { 14. SUBJECT TERMS } \\
\text { Space-time CE/SE method; Local mesh refinement }\end{array}$} & $\begin{array}{c}\text { 15. NUMBER OF PAGES } \\
12\end{array}$ \\
\hline
\end{tabular}





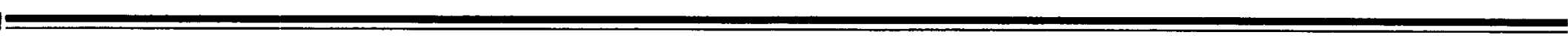

